\title{
Trends in reference evapotranspiration and its influential factors in Bangladesh
}

\author{
Jannatun Nahar Jerin ${ }^{1}$, H. M. Touhidul Islam ${ }^{1}$, Abu Reza Md. Towfiqul Islam ${ }^{1}$, Mehnaz \\ Abbasi Badhan ${ }^{1}$, Ronghao $\mathrm{Chu}^{2}$, Zhenghua $\mathrm{Hu}^{3}$, and Sobhy M. Ibrahim ${ }^{4}$ \\ ${ }^{1}$ Begum Rokeya University \\ ${ }^{2}$ Anhui Meteorological Bureau \\ ${ }^{3}$ Nanjing University of Information Science and Technology \\ ${ }^{4}$ King Saud University
}

August 28, 2020

\begin{abstract}
Despite a substantial effect of reference evapotranspiration (ETref) in irrigation practices and hydrological processes, trends and the causes of such trends in ETref are scarcely investigated in Bangladesh. The spatiotemporal trends in ETref, climatic factors influencing the variations in ETref were investigated based on daily climate datasets from 18 sites during $1980-2017$. Modified Mann-Kendall, linear regression, Morlet wavelet analysis (MWA) and cross wavelet transform model were employed to appraise temporal variations in ETref and the influential climatic variables. The empirical Bayesian kriging model was used to understand the spatial variations of ETref on the annual and seasonal time scales. The stepwise regression and partial correlation coefficient (PCC) were adopted to identify factors influencing the variations in ETref. The analysis showed a decrease in annual (-1.19 mm/year) and seasonal (-0.40 mm/decade for pre-monsoon, $-0.47 \mathrm{~mm} /$ decade for post-monsoon, $-0.50 \mathrm{~mm} /$ decade for winter) ETref except for monsoon in Bangladesh which is similar to "evapotranspiration paradox" observed in some locations. Results of trend analysis also revealed that though a rise in mean temperature (MT), a significant decline in sunshine duration (SD) and wind speed (WS) are the major causes of the decrease in ETref. Spatially, the higher annual ETref was found in the southwestern region while the lower ETref was detected in the northwestern region. The significant periods of 1-3 and 3-5-year cycles were detected in the annual and seasonal ETref. The results exhibited a significant coherence between ETref with climatic variables at various time-frequency bands. Stepwise regression and PCC showed that the effect of climatic variables on ETref differs on the annual and seasonal scales whereas MT, RH, and SD mainly attributed to the variations ETref in Bangladesh. These outcomes are anticipated to be beneficial for irrigation designing a sustainable water practice considering the effects of climate change and anthropogenic contributions.
\end{abstract}

\section{Introduction}

Evapotranspiration (ET) acts as a linkage between the energy and hydrological balance which is the key contributing factor of water vapor to the atmospheric demand (Salam and Islam 2020). Reference Evapotranspiration (ETref) is a pivotal element for hydrological practice, water resources designing, watershed management, and agricultural sector (Islam et al. 2018; Li et al. 2018; Chu et al. 2019). It is not only the most critical factor hydrological research but also a critical factor in climatic research (Roudier et al. 2014). Understanding the variations in ETref is essential for water resource practices, hydrological processes and implementing adaptation of climate change measures (Islam et al. 2019).

ETref relies on some meteorological parameters like sunshine hour duration (SD), air temperature, relative humidity $(\mathrm{RH})$, rainfall $(\mathrm{R})$, and wind speed (WS). Moreover, the variabilities in ETref rely on those parameters and their exchanges. For example, the average temperature has elevated by $0.8^{\circ} \mathrm{C}$ since the $1980 \mathrm{~s}$, 
whereas the SD has declined by up to $20 \%$ during the several decades worldwide (Dodgshun 2017). The inconsistent variations in terms of radiative and aerodynamic parts of ETref have triggered a contradiction in the ETref trend in the world. Despite an increase in mean temperature, ETref has been observed to be declined in most regions of the globe in recent decades (Chu et al. 2019). Decreasing SD and WS have been found as the main driver of the "evapotranspiration paradox" in most other parts of the earth. The variations in climatic factors are not happening consistently in the globe. As for instance, change in RH is not significant globally, it is observed to enhance up to $2.0 \%$ per decade over the main part of the USA, China, and India in the last four decades. Diverse variations in climatic variables have triggered a significant increase in ETref in different countries e.g., Argentina (D'Andrea et al. 2019), South Korea (Ghafouri-Azar et al. 2018; Hwang et al. 2019), eastern Pakistan (Ahmad et al. 2019), and central India (Kundu et al. 2017), whereas a reduction in ETref has been observed in various countries e.g., Brazil (Cabral Júnior et al. 2019), Iran (Nouri and Bannayan 2019) and major regions of China ( $\mathrm{Li}$ et al. 2018; Yang et al. 2020). There is no variation in ETref noticed in several parts like Peninsula Malaysia (Pour et al. 2020) and the Mountains of Qilian in China (Lin et al. 2018). Both ascending and descending trends in ETref were also reported in several areas including Tibetan Highland (Zhang et al. 2019), and Huahe River basin (Chu et al. 2017).

The implications of ETref variation is much elevated in the subtropical sub-humid region, especially Bangladesh. Bangladesh hosts the different environments and an elevated content of species. These species have a slight climatic position and thus, highly susceptible to climatic variabilities. A small variation in ETref might have a huge effect on biodiversity and the ecosystem. However, only a few cited works have examined the changes of ET over Bangladesh. For instance, Rahman et al. (2019) reported a decreasing trend in ETref in most of the regions of the country. Published cited works associated with variations in ETref and the influential meteorological factors of such variations are yet scarce in Bangladesh. Considering this fact, and our research intends to close the gap.

Hydro-geologically, Bangladesh has an abundance of freshwater but excessive withdrawal reducing the level which becoming an alarming issue for the past few decades (Acharjee et al. 2017; Islam et al. 2019). Many studies have been reporting that the occurrence of drought is being frequent nowadays with a threat to agriculture as well as food security for Bangladesh reported by National Drought Mitigation Center (Uddin et al. 2020). For an agriculturally based country like Bangladesh, climate change is becoming a great threat to meet food security with an emerging huge population. Though climate change has both positive and negative impacts on agriculture, the negative effect is more prominent (Islam et al. 2017). Though a vivid number of studies have been performed to insights into the variations in rainfall and temperature in Bangladesh, appraisal of trends in ETref and the influencing forces behind those trends has not still investigated. Thus, it is essential to figure out ETref variations extensively and how the meteorological factors affecting these alternations as ETref playing a major function in the water cycle as well as hydrological processes. ETref is highly sensitive to variations in meteorological parameters that are pivotal for its computations. Now the open question arises in this context: Are all sites of Bangladesh changed in ETref trend or part of the country both annually and seasonally? Which meteorological variables caused ERref variations? What are the meteorological variables that influencing the ETref most? Is there any periodicity of ETref in the seasonal and annual scales? The answers to these questions remain unsolved. To design a water resource plan for Bangladesh, a comprehensive study of ETref trends and the affecting meteorological variables across Bangladesh is needed. Keeping these in mind, the key objectives of our work are (1) to quantify spatiotemporal trends of ETref and other climatic variables in Bangladesh from 1980-2017; (2) to analyze periodicity of ETref at the annual and seasonal scales under changing climate condition; (3) to detect the climatic variables that are most influencing ETref in Bangladesh.

\section{Materials and methods}

\subsection{Study area description}

Bangladesh, positioned in subtropics has a hot and warm sub-humid climate which is mostly triggered by the monsoonal system, modulating topography, and complex hydrogeologic setting (Fig. 1). Most parts of the country are floodplain, excluding for few hilly regions in the southeastern and eastern areas (Rahman 
and Islam, 2019). The daily temperature in the country ranged between $18{ }^{\circ} \mathrm{C}$ and $32{ }^{\circ} \mathrm{C}$ with a mean of $26^{\circ} \mathrm{C}$ whereas the mean annual rainfall was $2400 \mathrm{~mm}$ (Islam et al. 2020a). The climate of the country is predominated by four seasons such as pre-monsoon hot monsoon (March-May), rainy and moist monsoon period (June-August), and post-monsoon (September- November) and dry winter (December-February) seasons (Islam et al. 2020a). The region is characterized by Hot and humid monsoon with high rainfall and dry and mild cold winter. Seasonal variations in temperature and rainfall are distinct features. Outlines of seasonal wind integrated with local geographic features create an irregular rainfall pattern over Bangladesh. The wind is normally light which varies its direction and intensity based on monsoonal circulation. The sunshine hour duration is elevated because of its position near to the equatorial belt.

\subsection{Data sources and quality control}

Daily meteorological dataset of five parameters including mean temperatures $\left({ }^{\circ} \mathrm{C}\right)$, rainfall $(\mathrm{mm})$, relative humidity $(\%)$, wind speed $\left(\mathrm{km} \mathrm{day}^{-1}\right)$, and sunshine $\left(\mathrm{h}\right.$ day $\left.^{-1}\right)$ were obtained from the Bangladesh Meteorological Department (BMD). Though BMD has 43 weather stations throughout the country, the majority of the stations are unevenly distributed, some of them are newly equipped and few stations have no longer datasets. In this study, we used 18 weather stations dataset that measures meteorological parameters essential for calculating ETref (Fig. 1). The problem arises when missing data exist. If the missing data was observed in any year $>2 \%$, the data of that particular year was omitted. When the data comprised of $>2 \%$ missing values (Rubin et al., 2007), the supplied estimated data might have inaccurate, subsequently inaccurate outputs may provide. Rahman and Islam (2019) also employed the threshold level for showing missing precipitation in Bangladesh. Other studies applied to the threshold of $2 \%$ for data quality control purposes (Vieira, 2017). After initial scrutiny, the availability of weather datasets at various sites was observed to range between 30 to 48 years. We used 37 years of daily climatic records during 1980-2017. It is noted that for a good representation of the data stations were selected which are uniformly scattered all over the country. However, quality control of the dataset was primarily undertaken thoroughly by checking namely, positive values of parameters, for example, Tmin is lower than Tmax, and humidity is less than $100 \%$. Time series and homogeneity tests of the dataset were conducted to exhibit any anomaly in the dataset (Islam et al. 2020b). Besides, the quality appraisal of the dataset of the selected stations was performed using a subjective double mass curve procedure and the objective Standard Normal Homogeneity Test (SNHT) (Fig. S1). Each dataset was detected consistently to fit for quantitative appraisal. The SNHT and K-S tests among various subsets of datasets depicted no significant difference in those datasets for all the parameters at the $95 \%$ confidence level (Table S1). Hence, the quality of the datasets was achieved suitable for further appraisal.

\subsection{Calculation of Reference Evapotranspiration}

The measured ETref datasets were unavailable in Bangladesh, so, we use the FAO-56 Penman-Monteith (PM) method to compute ETref, that is highly acknowledged and widespread exercise when ETref calculations are unavailable. This method is suggested by FAO and many other studies i.e. Allen et al. (1998) and Feng et al. (2017). FAO suggested this method as the ideal tool to calculate ETref, which was performed fit for different climate settings and time step computations without any calibration and validation (Valiantzas 2013; Feng et al. 2017; Islam et al. 2019). The PM method is expressed in the following Eq. (1)-

$\mathrm{ET}_{o}=\frac{0.408\left(R_{n}-G\right)+\gamma \frac{900}{(T+273)} u_{2}\left(e_{s}-e_{a}\right)}{+\gamma\left(1+0.34 u_{2}\right)}$.

Where ETref is reference evapotranspiration $\left(\mathrm{mm} \mathrm{d}^{1}\right) ; \mathrm{R}_{\mathrm{n}}$ is net radiation $\left(\mathrm{MJ} \mathrm{m} \mathrm{m}^{2}\right)$; $\mathrm{G}$ is soil heat flux density $\left(\mathrm{MJ} \mathrm{m}^{2} \mathrm{~d}^{1}\right)$; $\mathrm{T}_{\text {mean }}$ is mean air temperature $(\mathrm{C})$; $\mathrm{e}_{\mathrm{s}}$ is saturation vapor pressure, $(\mathrm{kPa})$; $\mathrm{e}_{\mathrm{a}}$ is actual vapor pressure, $(\mathrm{kPa}) ; \mathrm{D}$ is slope of the saturation vapor pressure function $\left(\mathrm{kPa} \mathrm{C}^{1}\right)$; $\mathrm{g}$ is psychometrics constant $\left(\mathrm{kPa} \mathrm{C}^{1}\right) ; \mathrm{U}_{2}$ is wind speed at $2 \mathrm{~m}$ height $\left(\mathrm{m} \mathrm{s}^{1}\right)$.

Due to the lack of $\mathrm{U}_{2}$ data, $\mathrm{U}_{10}$ data was used for calculation by using the logarithmic vertical wind speed profile, the Eq. (2) is recommended by Allen et al. (1998):

$U_{2}=U_{z} \frac{4.87}{\operatorname{In}(67.8 z-5.42)}$ 
Where $\mathrm{z}$ is the height of measurement above ground surface $(\mathrm{m}), \mathrm{U}_{\mathrm{z}}$ is measured wind speed at $\mathrm{z} \mathrm{m}$ above ground surface $\left(\mathrm{m} \mathrm{s}^{1}\right), \mathrm{U}_{2}$ is the wind speed at a $2 \mathrm{~m}$ height $\left(\mathrm{m} \mathrm{s}^{1}\right)$.

The computation of the selected stations required in analyzing ETref followed the standard tools (Allen et al. 1998). The periodical and yearly ETref were computed by the daily ETref dataset. It should be noted that a season is denoted in the ideal climatological pathway: Pre-monsoon is represented as happening from March to May, monsoon season from June to August, post-monsoon season from September to November, and from December to February is known as winter (Islam et al. 2019).

\subsection{The Modified Mann-Kendall (MKK) test}

Hamed and Rao (1998) pioneered the MKK test was used which take in accordance all auto-correlation coefficients in time-series datasets. In this test, modified variance $(\operatorname{Var}(\mathrm{S}))$ is used for calculating statistics of the most common MK test (Islam et al. 2020a; Praveen et al. 2020). The following Eqs. (3-5) was used to calculate the modified coefficient of autocorrelation datasets:

$$
\begin{aligned}
& \operatorname{Var}(S)=\operatorname{Var}(S) \times\left(\frac{n}{n}\right) \text {. } \\
& \left(\frac{n}{n}\right)=1+\left(\frac{2}{n(n-1)(n-2)}\right) \times \sum_{k=1}^{n-1}(n-k)(n-k-1)(n-k-2)^{r} . \mathrm{k} \ldots \ldots \ldots \ldots \\
& r_{k}=\frac{\left(\frac{1}{n-k}\right) \sum_{i=1}^{n-k}\left(x_{i}-x\right)\left(x_{i+k}-x\right)}{\left(\frac{1}{n}\right) \sum_{i=1}^{n}\left(x_{i}-x\right)^{2}}
\end{aligned}
$$

Where, $\operatorname{Var}(\mathrm{S})$ is calculated via the Eq. (3), $\mathrm{nn}^{*}$ represents the modified coefficient of autocorrelated data, $r_{\mathrm{k}}$ represents the autocorrelation coefficient of $\mathrm{kth}$, and $\mathrm{x}$ represents the mean of time series. The significance of autocorrelation coefficient of $\mathrm{k}$ that $95 \%$ confidence level can be calculated by the following Eq.(6):

$$
\left(\frac{-1-1.96 \sqrt{n=k-1}}{n-k}\right) \leq r_{\mathrm{k}}(95 \%) \leq\left(\frac{-1-1.96 \sqrt{n=k-1}}{n-k}\right) .
$$

If the attained $r_{\mathrm{k}}$ follows the above situation, $95 \%$ confidence level data can be obtained. Else, the data are dependent and the impact of autocorrelation coefficient with different lags should be eradicated to estimate the trend of time series. Lastly, a trend in time series data can obtained if $\mathrm{Z}$ is less or greater than the $\mathrm{Z}$ of standard normal distribution at $95 \%$ confidence level.

\subsection{Linear regression analysis}

A time series $\mathrm{y}_{1}, \mathrm{y}_{2} \ldots, \mathrm{y}_{\mathrm{i}}, \ldots, \mathrm{y}_{\mathrm{n}}$ can be calculated by the Eq. (7) used by Tang et al. (2011):

$\hat{y_{n}}=a_{0}+a_{1} t+\ldots+a_{m} t^{n} \quad(m<n)$

Where $\mathrm{y}_{\mathrm{i}}=$ the response variable (i.e. $\mathrm{ET}_{0}$, precipitation), $\mathrm{t}=$ the year. Generally, the linear trend of a time series can be estimated by the least square method and can be expressed by a linear regression Eq. (8) as:

$\hat{y_{n}}(t)=a_{0}+a_{1} t$

where the slope $a_{1}$ is the estimated trend, and a1 $\times 10$ is called climate tendency rate, which presents its change rate. Negative value of $a_{1}$ represents a negative trend while positive value of $a_{1}$ represents a positive trend.

\subsection{Wavelet analysis}

"Morlet wavelet" by Wang et al. (2014) and Zhang et al. (2015) was used to conduct periodicity analysis on the annual and seasonal $\mathrm{ET}_{\text {ref }}$ variations. Continuous wavelet analysis (CWA) has localized in terms of time and frequency domains compared to moving filter analysis and Fourier analysis. It can be used to assess locations on time series dataset. For certain $\varphi(t)$, the wavelet transforms, wavelet coefficient and wavelet variance of meteorological time series dataset $f(k . t)(\mathrm{k}=1,2, \ldots \ldots, \mathrm{N}$, which denotes the time series data) were defined as the following Eqs. (9-11): 
$w_{f}(a, b)=|a|^{-1 / 2} t \sum_{k=1}^{n} f(k . t) \varphi\left(\frac{k . t-b)}{\alpha}\right.$

$w_{f}(a, b)=|a|^{-1 / 2} t \sum_{k=1}^{n} f(k) \cdot e^{\mathrm{ict}} \cdot e^{-t 2 / 2}$

$\operatorname{Var}(a)=\int_{\infty}^{+\infty}\left|w_{f}(a, b)\right|^{2} \mathrm{db}$.

Where, $a=$ scale factor representing the cycle length (periodicity), $b=$ time factor representing the time location), $\mathrm{W}_{\mathrm{f}}(\mathrm{a}, \mathrm{b})=$ the transformation coefficient, $\operatorname{Var}(\mathrm{a})=$ the variance of continuous wavelet analysis $\mathrm{c}$ $=$ the constant value

The transformation coefficient of CWA can be attained by $\mathrm{W}_{\mathrm{f}}(\mathrm{a}, \mathrm{b})$. The information about strength and phase of scale signals at various time period could be represented by the bar. Negative value (anti-phase) presents higher period whereas positive value (in-phase) denotes lower period. If $\mathrm{W}_{\mathrm{f}}(\mathrm{a}, \mathrm{b})=0$, it equals to the breakpoint. The variation rises significantly with the increasing of $\mathrm{W}_{\mathrm{f}}(\mathrm{a}, \mathrm{b})$.

After "Morlet wavelet" for CWA, then, we employed wavelet transform coherence (WTC) to check the corelationships of meteorological parameters that influence the variation in annual ETref (Rahman and Islam 2019; Uddin et al. 2020). WTC quantifies the covariance magnitude between two time-series which varies from 0 to $1\left(0 \leq R^{2} \leq 1\right)$. 0 refers to no coherence at all whereas 1 refers to perfect coherence. WTC is employed to analyze the co-relationship between two parameters. The calculated Eq. (12) for WTC is outlined as follows:

$R^{2}(m, n)=\frac{\mid S\left(\left.s^{-1} W_{\mathrm{xy}}(s)\right|^{2}\right.}{S\left(s^{-1}\left|W_{x}(s)\right|^{2} \cdot S\left(s^{-1}\left|W_{y}(s)\right|^{2}\right.\right.}$

where $x$ and $y$ are two time series with their respective wavelet transforms $W_{x}(s)$ and $W_{y}(s)$. Monte-Carlo (MC) simulation is applied for statistical significance in this study.

\subsection{Empirical Bayesian kriging (EBK) model}

In the present study, we used a robust novel interpolation method like Empirical Bayesian kriging (EBK) from the ArcGIS environment to confirm the robustness and visualize the spatial variability of meteorological variables and ETref. The EBK is a novel geostatistical interpolation technique that automating the utmost complicated feature of constructing a valid kriging model that can be thought of as the most challenging feature of spatial interpolation within the geostatistical method (Gupta et al., 2017). Moreover, unlike the other kriging approaches the EBK model need not adjust manually model variables rather it can automatically compute these variables within a manner of sub-setting and simulations (Gribov and Krivoruchko 2020)

\subsection{Attribution analysis}

Stepwise regression and partial correlation coefficient (PCC) suggested by Haan (1977); Xu (2011) and Herath et al. (2017) were used to understand the climatic variables influencing the variations in annual and seasonal ETref during 1980-2017 in Bangladesh. The PCC was based on a normalized time series dataset in this study.

\section{Results}

\subsection{Annual and seasonal trends ofreference evapotranspiration}

Fig. 2 shows the spatial distribution patterns of ETref on the annual scale, where the highest ETref was $1661 \mathrm{~mm}$ in Jessore station and the lowest was $1137 \mathrm{~mm}$ in Mymensingh station during the observation period. The higher spatial ETref variation was distributed in the southern portion while the north-western portion of Bangladesh showed lowermost ETref (Fig. 2a). In a seasonal scale, the ETref variations in the western portion were comparatively higher in the pre-monsoon than that of other seasons. Spatially, the dispersal pattern of pre-monsoon ETref was analogous to the annual ETref pattern (Fig. 2b). The monsoon ETref showed a heterogeneous spatial pattern during the observation period (Fig. 2c). The highest ETref in post-monsoon can be found at the Coxs-Bazar stations, which are located in the southern part of Bangladesh and post-monsoon ETref also showed the analogous spatial pattern of annual ETref (Fig. 2d). The northern and northwestern parts of Bangladesh showed a narrower ETref spatial distribution and opposite to eastern 
and southern regions in monsoon season. The winter ETref exhibited a noteworthy spatial distribution in the southern part while the northern part still shows the lowest value with a complex spatial pattern (Fig. 2e). The ETref was lowest in the northern portion, however the south and western parts indicated the maximum ETref on a yearly and seasonal basis.

Table 1 showed the Modified Mann-Kendall (MK) trend test results for each site of seasonal ETref in Bangladesh. The ETref in the winter season showed a notable spatial distribution in the southern part while the northern part showed the lowest rate (Table 1). During the pre-monsoon, ETref declined $0.05 \mathrm{~mm}$ per year and $89 \%$ of the sites showed a decreasing trend which was mostly distributed in the northwestern part. Each region exhibited the minimal rate of mean ETref trend in the pre-monsoon season except for the western part. Western part showed a higher ETref in the pre-monsoon season than the other seasons. Overall, the ETref had a decreasing trend all over the country. The rise of mean temperature, sunshine duration, and relative humidity in the western part of Bangladesh resulted the rise of ETref in this region.

The results of linear trends showed a declining trend in ETref at a significance level of $1.19 \mathrm{~mm}$ per decade (Fig. 3). The yearly ETref was decreasing throughout the study period, but only $72 \%$ of the sites showed a noteworthy level $(\mathrm{p}<0.05)$ (Table 1$)$. Excluding for the post-monsoon, the periodical ETref rose in all seasons. The ETr displayed a significantly declining tendency and the rate of magnitude were $-0.47 \mathrm{~mm}$, $-0.47 \mathrm{~mm}$, and -0.50 per decade respectively in post-monsoon, pre-monsoon and monsoon seasons except for winter. Across the seasons, the southeast portion showed a noteworthy rising trend $(\mathrm{p}<0.05)$ whereas the central portion showed a declining trend. The highest ETref in post-monsoon can be found at the Coxs-bazar station, which are located in the southern part (Table S2). Spatially, the ETref distribution were narrower in the north-eastern and western parts than other regions, where the south and western sections exhibited the maximum ETref annually and seasonally.

\subsection{Annual and seasonal trends of climatic variables}

The spatial distribution maps of climatic variables are shown in Fig. 4. The MT increased from the northern to the southern region in Bangladesh with little fluctuating temperature (Fig. 4a). The highest RH was witnessed in the southern part and the lowest in the central part with a complicated spatial pattern (Fig. $4 b)$.

The low SD was detected in the southern and northeastern regions while the high SD was found in northwestern and southeastern with decreasing spatial pattern from north to east during the study period (Fig. 4c). There was an irregular spatial pattern observed in rainfall where the lowest concentration of $\mathrm{R}$ was found in the western region and the highest concentration of $\mathrm{R}$ was detected in the eastern portion of Bangladesh (Fig. 4d). The spatial variation of wind speed was quite complicated and similar to MT and higher values were found in the southern region and lower in the northern region (Fig. 4e). During the winter season, the northeasterly winds prevail over the country blowing from land to sea except for northern areas where mainly easterly wind prevails.

The annual MMK trend test results for climatic parameters during 1980-2017 showed in Table 2. Except for three stations (Mymensingh, Patuakhali and Rangamati), all the 15 sites showed a noteworthy rising tendency in the MT. A decreasing trend of R was seen almost $50 \%$ of the study area. A downward trend of $\mathrm{SH}$ and WS also been observed in most of the stations and also in a substantial rate.

The results of linear regression show that the MT significantly increased in most meteorological stations (Fig. 5). Though the MT fluctuated throughout the study period but statistically rising tendency was observed and the rate was $0.12 \mathrm{deg} \mathrm{C} /$ decade that noteworthy. The SD was declining in several locations where the lowest was observed at the Rangamati region at a rate of 2.89 hours/decade. The maximum $\mathrm{RH}$ level was located at the Mymensing region (0.27\%), while the minimum (-0.15\%) was found in Dhaka region. A slightly decreasing trend of rainfall was observed during the period 1980-2017 in the study area in 13 sites. But the all sites neither displayed a major rising nor a declining pattern of rainfall (Fig. 5).

\subsection{Periodicity of Annual and seasonal reference evapotranspiration}


To examine the periodicity of ETref in Bangladesh, the yearly ETref series of the study period from 1980-2017 was displayed by the Morlet wavelet transform (MWT). Fig. 6 (a) shows the MWT of ETref which exhibits significant changes in the frequency bands of 1-3, and 3-5-year periods during 1988-1994 and 2006-2009. Fig. 6(b) shows the significant changes of ETref in pre-monsoon, prominent in frequency domains of 0-5 and 5-8 and 8-12 during 1994-1998, 1990-2004, and 1994-2002 periods of observation respectively, characterized by an "I" and an elongated oval-shaped dark red color. Fig. 6(c) shows MWT of ETref in monsoon season, exhibiting small but significant changes in the frequency domains of 2-3.5, 2-3, and 2-4 years during 19871993, 2001-2003, and 2006-2009 periods respectively, denoted by the small and scattered islands of red color contours inside of the borders. Fig. 6(d) shows the little changes of ETref in post-monsoon, most prominent in the frequency band of 0-1.5 years during the 1988-1993 period of observation, represented by an edge dark red color half contour. Fig. 6(e) shows a continuous wavelet transform of ETref in the winter season, showing two small but significant changes in the frequency bands of 1-3 and 3-5 years during 1998-2001, and 2005-2009 periods respectively, characterized by the small and central and right sides island of red color contours along its margin.

\subsection{Influence of meteorological parameters on ETref}

The wavelet transforms coherence (WTC) between meteorological parameters and ETref in Bangladesh are outlined in Fig 7. The small arrows found in Fig. 7a exhibited the direction of correlation between sunshine duration (SD) and annual ETref where the colored bar on the right top side denotes the strength of this correlation. The rightward movement of arrows inside the contour represented a positive correlation between SD and ETref (in-phase) in the time-frequency domains of 0-4 and 4-5 years, during the 1998-1994 and 20062009 periods. Black cone shape was observed in the top left side which was called "cone of influence" and means the confidence level and significance edge effects in its margin.

Fig. $7 \mathrm{~b}$ depicts that the small arrows towards the right side, indicating a non-significant positive correlation (in-phase) between wins speed (WS) and the ETref in the time-frequency band of 1-4 year to onwards during 1990-1994 of the observation periods. Non-significant edge shaped effects in the left side top corner are also detected in the same frequency band before 1995s.

Fig. 7c reveals that the small arrows towards the right side, implying a significant positive correlation (in-phase) between mean temperature and the ETref in the time-frequency band of 3-5 years during the period 2006-2011. The relative humidity (RD) and the ETref are anti-phase correlation as represented by the arrows towards the left side in the circle donated on the left side top corner of the Fig. $7 \mathrm{~d}$ and inside the cone of influences. Red color contour is characterized by the colored bar on the left side which suggesting a strong negative correlation in the time-frequency band of 0.5-3.5 years and onwards during 1987-1994 of the observation periods. Fig. 7e shows that left side arrows, indicating a negative significant correlation (anti-phase) between rainfall and the ETref in the frequency band of 0-3.5 years to onwards during 1989-1997 of the observed periods.

Table 3 shows the partial correlation results for ETref and meteorological parameters in Bangladesh. The amount of contribution of meteorological factors differs from the temporal changes in the time series to variation ETref in Bangladesh. The largest significant partial correlation matrix value was observed between MT and ETref $(r=0.797$ at the annual scale; $r=0.734$ at the seasonal scale for winter, $\mathrm{p}<0.01)$. For summer, spring, and winter season 0.987, 0.930, and 0.407 values were obtained respectively. Both annual and winter seasonal ETref variation was strongly influenced by mean temperature except for other seasons.

The second highest partial correlation was observed among SD and ETref, ( $\mathrm{r}=0.654$ at the annual scale, $\mathrm{p}, 0.01, \mathrm{r}=0.407$ for post-monsoon, $\mathrm{p}>0.05$, and 0.591 for winter, $\mathrm{p}<0.01$ ). Except for the pre-monsoon and monsoon seasons, the seasonal contribution of SD was the main factor in ETref variation in Bangladesh. By contrast, the $\mathrm{RH}$ is negatively dominant climatological factors that had an impact on ETref variation during the annual and seasonal scales ( $\mathrm{r}=-0.677$ at the annual scale, $\mathrm{p}<0.01, \mathrm{r}=-0.376$ for pre-monsoon, $\mathrm{r}=-0.313$ for winter, $\mathrm{p}<0.05)$. WS had a little contribution to the variation of ETref during the annual and seasonal scales 
except for winter. However, no significant relationship was detected between rainfall and ETref during the observation period of 1980-2017 in Bangladesh except for winter. So, it can be said that MT for the annual, and winter and SD for annual, post-monsoon and winter were mostly prominent meteorological parameters in the ETref variations of the country. Although WS had a little contribution to the variation of ETref during the annual and seasonal scales except for winter. Based on the outcomes of partial correlation matrix results, overall MT, RH, and SD are significant meteorological factors in the ETref variations on annual and seasonal periods during the study period. WS and rainfall only influenced the variations in ETref during winter. However, MT, RH, and SD play a major influencer in changing ETref whereas WS and rainfall act as a minor role in the variation of ETref in Bangladesh during the period of 1980-2017.

Table 4 outlines the standardized coefficient values of the five meteorological parameters for variations in ETref. The MT, SD, and RH were the greatest dominant climatological factors that influenced the variations in ETref on an annual basis, with standardized coefficient values of $0.550,0.472$, and -0.384 respectively. Seasonally, RH declined in winter when MT boosted and both factors were dominating and the coefficient values were -0.488 and 0.488 , respectively. The $\mathrm{RH}$ was the most prominent parameter on ETref variation in the pre-monsoon and monsoon, with the elevated standardized coefficient values of -0.418 and -0.331, respectively. Similarly, the SD was the key influencer on ETref changes during the post-monsoon. Surprisingly, in the winter, RH was the greatest forceful parameter, with a high coefficient value of 0.670. At the same time, the MT was the main factor for ETref variation during the winter, with a coefficient value of 0.593 .

The decline in ETref on the annual time scale and during the post-monsoon and winter seasons was affected by RH, MT, and SD. Winter ETref showed a significantly declining trend at the seasonal scale. WS exhibited no alteration on the yearly or seasonal scale. On the whole, ETref changes were affected by the coupling effects of considerably rising MT, and SD and declined RH in Bangladesh. WS is a little contributor to the ETref variation in Bangladesh. Rainfall had no effect on ETref variation as a meteorological parameter, but it plays as a predominant role for drought events in western Bangladesh.

\section{Discussion}

This study aims to explore the spatiotemporal variation of ETref and other climatic variables that influence ETref. We focused to identify the seasonal and annual trend patterns of ETref of the study area. It was observed that the MT had an increasing trend in most locations in the country. Many studies also reported that global temperature was increasing substantially over the last few decades in an alarming rate which resulting not only altering the global water budget but also the more frequent drought and flood (IPCC 2007; Feng et al. 2014; Islam et al., 2019). Recently, a study by Islam et al. (2017) also found frequently and intense droughts phenomena occurring in Bangladesh that also support our result of an increasing trend of MT which might result from the severe change of climatic parameters throughout the country.

Wind speed and sunshine hours were reducing considerably in most of the regions and it can be alarming under climate change scenario. Syeda and Nasser (2012) reported that a significant decreasing trend of the sunshine hour had been observed over Bangladesh that might be the result of the increasing air pollution in our atmosphere and also the soared anthropogenic activities for the past few decades. Lian et. Al. (2015) studied that characteristics of changing climate ought to change the water cycle which can be resulted in frequent occurring of drought and flood also indicate the same changes occurring like our study. Most areas in Bangladesh experiencing a considerable declining of SD coupling with the rising temperature. Many scientists i.e. Jhajharia et al. (2012) and Chu et al. (2017), considered that the rising of aerosols and clouds resulting from air pollution was the main reason behind the lowering SD.

A significantly decreasing trend of ETref also found in the study done by Rahman et al. (2019) which also supports our findings. A slightly increasing trend of ETref was found northeast to the southwest part of Bangladesh that contradicted the studies done by Yang et al. (2013). But Mojid et al. (2015) found an increasing trend of ETref in Bogra and Rangpur stations similar to our studies. Some published works like Fan and Thomas (2013) and Tao et al. (2015), it was evident that SD played a pivotal role in quantifying 
ETref variations in several locations of Bangladesh. According to Tao et al. (2015), it is evident that SD and WS are the most prominent parameters than MT and RH which act behind the disparity of ETref.

Nonetheless, various scholars in their works (Chu et al. 2017; Li et al. 2018) confirmed that SD and WS act as a key influencer about ETref which is analogous to our study. On the other hand, The PCC analysis revealed that $\mathrm{SD}, \mathrm{MT}$, and $\mathrm{RH}$ were the main drivers of ETref and WS had little effect. The declining amount of RH in the air also influencing the reduced ETref as like as the other climatic variables. Though an overall decreasing trend of ETref was found in the study area coupled with increasing temperature which should be taken under consideration by the policymaker to manage water for future agricultural water practice and drought risk reduction phases.

The decrease in SD and WS was found in the study area which should resultant a decline ETref but a significant increase in MT offset the impact and followed the "evapotranspiration paradox" in Bangladesh which is supported the study conducted by Herath et al. (2017), Feng et al. (2017). Studies by Roderick and Farquhar (2002) establish the fact that a decline in SD resulted in the lessening ETref which were similar to our study.

The studies done by Rahman et al. (2019) and Mojid et al. (2015) showed that MT, SD, and WS had a significant influence on the ETref occurring that also support our study. The WS and SD were declining notably in some parts of Bangladesh. In the meantime, in Bangladesh strange fluctuations were noticed in MT and SD that can be triggered by global warming. Changes in hydrological processes resulted from changing climate ought to enhance the frequency of drought, flood and reallocating the water resources in Bangladesh (Islam et al., 2019).

\section{Conclusion}

We found decreased in ETref with time across Bangladesh which is similar to the "evapotranspiration paradox" in different portions of the globe. Though a significant rise in MT, but SD, R, and WS was found as the key influential factors of decreasing annual and seasonal ETref in Bangladesh. This study indicates that the declining SD and WS would gradually decrease ETref in Bangladesh. Spatially, the southern part of Bangladesh reflected the higher ETref while the northwestern region exhibited the lower ETref on an annual and seasonal scale. In a seasonal scale, the ETref in the western part tends to be elevated in the pre-monsoon compared to other seasons. Moreover, it is interesting to note that decline in ETref across Bangladesh in the last four decades has been prominent during the all seasons except for monsoon. The declining ETref might have implications in atmospheric evaporation balance, irrigation, and reservoir management required in different regions of Bangladesh. A decrease in ETref and variations in water shortage can influence the hydrologic cycle in the study region which has created an environmental crisis. The outcomes of the research can be useful for designing adaptation measures of climate change and also mitigating drought effects on agricultural water resources and ecosystems. The coupling of satellite-derived ETref and climatic datasets can be utilized for better evaluating spatial variations in ETref and climatic variables in the future study. Also, research should be carried out to appraise the variations in soil moisture water balance because of a decline in ETref for evaluating the effects of decreasing ETref on irrigation practices, hydrological system, and drought adaptation in Bangladesh, especially in the northwest region.

\section{Acknowledgement}

We would like to acknowledge the Bangladesh Meteorological Department (BMD) for sharing climate dataset used in this research work. This work was supported by Researchers Supporting Project number (RSP2020/100), King Saud University, Riyadh, Saudi Arabia. We also acknowledge to the Begum Rokeya University, Rangpur, Bangladesh, for different forms of support during the study period.

\section{Conflict of interest}

None

Data availability 
The data are available from the corresponding author upon reasonable request

\section{References}

Acharjee TK, Halsema G, Ludwig F, Hellegers P (2017) Declining trends of water requirements of dry season Boro rice in the north-west Bangladesh. Agric Water Manage 180:148-159

Ahmad MD, Kirby JM, Cheema MJM (2019) Impact of agricultural development on evapotranspiration trends in the irrigated districts of Pakistan: evidence from 1981 to 2012. Water Int 44:51-73. doi:10.1080/02508060.2019.1575110

Allen RG, Pereira LS, Raes D, Smith M (1998) Crop evapotranspiration: guidelines for computing crop water requirements. FAO Irrigation and Drainage Paper 56, FAO - Food and Agriculture Organization of the United Nations, Rome (9): pp300, D05109.

Cabral Junior JB, Silva CMS e, de Almeida HA, Bezerra BG, Spyrides MHC (2019) Detecting linear trend of reference evapotranspiration in irrigated farming areas in Brazil's semiarid region. Theor Appl Climatol 138: $215-225$.

Chu R, Li M, Shen S, Islam ARMT (2017) Quantifying climatic impact on reference evapotranspiration trends in Huai River Basin of Eastern China. Water 10:144

Chu R, Li M, Islam ARMT, Fei D, Shen S (2019) Attribution analysis of actual and potential evapotranspiration changes based on the complementary relationship theory in the Huai River Basin of eastern China. Int J Climatol 39: 4072-4090

Dodgshun J (2017) The stilling: global wind speeds slowing since 1960. Horiz Mag Horiz EU Res Innov Mag. https://phys.org/news/2017-10-stilling-global.html.

Fan ZX, Thomas A (2013) Spatiotemporal variability of reference evapotranspiration and its contributing climatic factors in Yunnan Province, SW China, 1961-2004. Clim Chang 116(2): 309-325. doi:10.1007/s10584012-0479-4

Feng L, Li T, Yu WD (2014) Cause of severe droughts in Southwest China during 1951-2010. Clim Dyn 43: 2033-2042

Feng Y, Cui NB, Zhao L, Gong DZ, Zhang K (2017) Spatiotemporal variation of reference evapotranspiration during 1954-2013 in Southwest China. Quat Int 441: 129-139.

Ghafouri-Azar M, Bae D-H, Kang S-U (2018) Trend analysis of long-term reference evapotranspiration and its components over the Korean Peninsula. Water 10 :1373

Gribov A, Krivoruchko K (2020) Empirical Bayesian kriging implementation and usage. Sci Total Environ 137290. doi:10.1016/j.scitotenv.2020.137290

Gupta A, Kamble T, Machiwal D (2017) Comparison of ordinary and Bayesian kriging techniques in depicting rainfall variability in arid and semi-arid regions of north-west India. Environ Earth Sci 76(15). doi:10.1007/s12665-017-6814-3

Haan CT (1977) Statistical methods in hydrology. Iowa State University Press, Ames, IA

Hamed KH, Rao AR (1998) A modified Mann-Kendall trend test for autocorrelated data. J Hydrol 204:182196. https ://doi. org/10.1016/S0022 -1694(97)00125 -X

Herath IK, Ye X, Wang J (2018) Spatial and temporal variability of reference evapotranspiration and influenced meteorological factors in the Jialing River Basin, China. Theor Appl Climatol 131:1417-1428. https://doi.org/10.1007/s00704-017-2062-4

Hwang JH, Azam M, Jin MS, Kang YH, Lee JE, Latif M, Ahmed R, Umar M, Hashmi MZ (2019) Spatiotemporal trends in reference evapotranspiration over South Korea. Paddy Water Environ 1-25. 
doi:10.1007/s10333-019-00777-4

IPCC (2007) Climate change 2007-the physical science basis. Contribution of working group I to the fourth assessment report of the IPCC. Cambridge University Press

Islam ARMT, Ahmed I, Rahman MS (2020b) Trends in cooling and heating degree-days overtimes in Bangladesh? An investigation of the possible causes of changes. Natural Hazards 101:879-909. doi: 10.1007/s11069-020-03900-5

Islam ARMT, Shen S, Yang S (2018) Predicting design water requirement of winter paddy under climate change condition using frequency analysis in Bangladesh. Agric Water Manage 195(C):58-70

Islam ARMT, Shen S, Yang S, Hu Z, Chu R (2019) Assessing recent impacts of climate change on design water requirement of Boro rice season in Bangladesh. Theor Applied Climate 138 (1-2): 97-113. doi: 10.1007/s00704-019-02818-8.

Islam ARMT, Shen S, Hu Z, Rahman MA (2017) Drought hazard evaluation in Boro paddy cultivated areas of Western Bangladesh at current and future climate change conditions. Adv Meteorol 2017. https:// doi.org/10.1155/2017/3514381

Islam ARMT, Rahman MS, Khatun R, Hu Z (2020a) Spatiotemporal trends in the frequency of daily rainfall in Bangladesh during 1975-2017. Theoretical and Applied Climatology. http://dx.doi.org/ 10.1007/s00704020-03244-x

Jhajharia D, Dinpashoh Y, Kahya E, Singh VP, Fakheri-Fard A (2012) Trends in reference evapotranspiration in the humid region of northeast India. Hydrol. Process. 26, 421-435. https://doi.org/10.1002/hyp.8140

Kisi O (2016) Modeling reference evapotranspiration using three different heuristic regression approaches. Agric Water Manag 169:162-172

Kundu S, Khare D, Mondal A (2017) Interrelationship of rainfall, temperature and reference evapotranspiration trends and their net response to the climate change in Central India. Theor Appl Climatol 130 :879-900. doi:10.1007/s00704-016-1924-5

Li M, Chu R, Shen S, Islam ARMT (2018) Dynamic analysis of pan evaporation variations in the Huai River Basin, a climate transition zone in eastern China. Sci Total Environ 625: 496-509. doi: 10.1016/j.scitotenv.2017.12.317

Lian Y, You JY, Lin K, Jiang Z, Zhang C, Qin X (2015) Characteristics of climate change in southwest China karst region and their potential environmental impacts. Environ Earth Sci 74 (2) :937-944

Lin P, He Z, Du J, Chen L, Zhu X, Li J (2018) Impacts of climate change on reference evapotranspiration in the Qilian Mountains of China: Historical trends and projected changes. Int J Climatol 38:2980-2993. https://doi.org/doi:10.1002/joc.5477

Liu BH, Xu M, Henderson M, Gong WG (2004) A spatial analysis of pan evaporation trends in China, 1955-2000. J Geophys Res 109: D15102

Mojid MA, Rannu RP, Karim NN (2015) Climate change impacts on reference crop evapotranspiration in northwest hydrological region of Bangladesh. Int J Climatol 35:4041-4046. https ://doi. $\operatorname{org} / 10.1002 /$ joc. 4260

Nouri M, Bannayan M (2019) Spatiotemporal changes in aridity index and reference evapotranspiration over semi-arid and humid regions of Iran: trend, cause, and sensitivity analyses. Theor Appl Climatol 136:1073-1084. doi:10.1007/s00704-018- 2543-0

Pour SH, Wahab AKA., Shahid S, Ismail ZB (2020) Changes in reference evapotranspiration and its driving factors in peninsular Malaysia. Atmospheric Research 105096. doi:10.1016/j.atmosres.2020.105096 
Praveen B, Talukdar S, Shahfahad (2020) Analyzing trend and forecasting of rainfall changes in India using non-parametrical and machine learning approaches. Sci Rep 10: 10342.

Rahman MA, Yunsheng L, Sultana N, Ongoma V (2019) Analysis of reference evapotranspiration (ET0) trends under climate change in Bangladesh using observed and CMIP5 data sets. Meteorol Atmos Phys 131: $639-655$.

Rahman MS, Islam ARMT (2019) Are precipitation concentration and intensity changing in Bangladesh overtimes? Analysis of the possible causes of changes in precipitation systems. Sci Total Environ 690370387.

Roderick ML, Farquhar GD (2002) The cause of decreased pan evaporation over the past 50 years. Science 298 (5597): 1410e1411

Roudier P, Ducharne A, Feyen L (2014) Climate change impacts on runoff in West Africa:a review. Hydrol Earth Syst Sci 18: 2789-2801

Rubin LH, Witkiewitz K, Andre JS, Reilly S (2007) Methods for handling missing data in the behavioral neurosciences: Don't throw the baby rat out with the bath water. J Undergrad Neurosci Educ 5: A71

Salam R, Islam ARMT (2020) Potential of RT, Bagging and RS ensemble learning algorithms for reference evapotranspiration prediction using climatic data-limited humid region in Bangladesh. J Hydrol https://doi.org/10.1016/j.jhydrol.2020.125241

Sentelhas PC, Gillespie TJ, Santos EA (2010) Evaluation of FAO Penman-Monteith and alternative methods for estimating reference evapotranspiration with missing data in Southern Ontario, Canada. Agric Water Manag 97(5):635-644. doi:10.1016/j.agwat.2009.12.00

Syeda JA, Nasser M (2012) Trend and Variability Analysis and Forecasting of Sunshine Hour in Bangladesh. in: Journal of Environment, Science and Natural Resources 5(2): 109-118

Tang B, Tong L, Kang SZ, Zhang L (2011) Impacts of climate variability on reference evapotranspiration over 58 years in the Haihe river basin of north China. Agric Water Manag 98: 1660-1670

Tao XE, Chen H, Xu CY, Hou YK, Jie MX (2015) Analysis and prediction of reference evapotranspiration with climate change in Xiangjiang River Basin, China. Water Science and Engineering 8(4):273-281. doi:10.1016/j.wse.2015.11.002

Thomas A (2000) Spatial and temporal characteristics of potential evapotranspiration trends over China. Int J Climatol 20(4):381-396

Uddin MJ, Hu J, Islam ARMT, Eibek KU, Zahan MN (2020) A comprehensive statistical assessment of drought indices to monitor drought status in Bangladesh. Arab J Geosci 13. https://doi.org/10.1007/ s12517-020-05302-0

Valiantzas JD (2013) Simplified forms for the standardized FAO-56 Penman-Monteith reference evapotranspiration using limited weather data. J Hydrol 505: 13-23

Vieira ET (2017) Introduction to real world statistics: With step-by-step SPSS instructions Routledge., New York

Wang LZ, Cao LG, Deng XJ, Jia PH, Zhang W, Xu XW, Zhang KX, Zhao YF, Yan BJ, Hu W, Chen YY (2014) Changes in aridity index and reference evapotranspiration over the central and eastern Tibetan Plateau in China during 1960-2012. Quat Int 349: 280-286.

\section{Hosted file}

Figure paper_08_24_2020_final.docx available at https://authorea.com/users/353695/articles/ 477479-trends-in-reference-evapotranspiration-and-its-influential-factors-in-bangladesh 


\section{Hosted file}

Table_08_25_2020_final.docx available at https://authorea.com/users/353695/articles/477479trends-in-reference-evapotranspiration-and-its-influential-factors-in-bangladesh 